\title{
INTEGRATED METHODOLOGICAL FRAMEWORK FOR SMART CITY DEVELOPMENT
}

\author{
Zineb Korachi and Bouchaib Bounabat \\ ALQUALSADI Team, ADMIR Laboratory Rabat Information Technology Center \\ ENSIAS/Mohamed V University in Rabat Rabat, Morocco
}

\begin{abstract}
Making a city smart requires a strategy to meet the problems generated by the urban population growth and rapid urbanization. Many cities are treating projects of city transformation into a smart city as typical IT projects. In fact, there is a basic challenge of understanding the drivers behind city transformation and building a solid strategy planning to support and guide this transformation. To meet these challenges, this work proposes a methodology for defining and evaluating digital strategies for building smart cities. It presents how to develop and implement strategies for smart city development. Despite extensive and deep research on cities' successful transformation into smart cities, a gap exists on the methodology that the cities follow in transforming their services into digital services and making them smarter. This work builds on an integrative literature review of smart cities and digital strategies to propose an integrated methodology for smart cities development.
\end{abstract}

\section{KEYWORDS}

Digital Strategy, Smart City, Smart City Strategy, Key Performance Indicators (KPIs), Smart City Evaluation, City Dashboard

\section{INTRODUCTION}

Today, $55 \%$ of the world's population lives in urban areas, a proportion that is expected to increase to $68 \%$ by 2050 (UN DESA, 2018). This rapid urbanization is adding pressure to the existing resource base while increasing the demand for energy, water, sanitation, and public services such as education and health care (ITU-T FG-SSC, 2015a). To meet the growing needs associated with the increasing urban population, cities require an innovative strategy to achieve smart sustainable development, cities need transforming their services towards smart services.

Currently, the city's systems operate within silos and there is little or no cooperation between them (Budde, 2019). ICT (Information and Communication Technologies) can be the bridge between these silos which allow managing the city in a better way. ICT is able to create interoperability between silos via different technologies and frameworks like EAI (Enterprise Application Integration) and SOA (Service-Oriented Architecture Concept). The interrelationship between a smart city's core systems is taken into account to make them smarter (Chourabi et al., 2012). No system operates in isolation. In this sense, Kanter and Litow (Kanter and Litow, 2009) consider a smarter city as an organic whole — as a network, as a linked system.

Although there are several works on cities' successful transformation into smart cities, there is still not a clear and integrative methodology for smart city development. This paper attempts to start filling this gap by providing an integrated methodological framework for smart city development based on the exploration of an extensive array of literature from various fields such as smart cities, digital strategies, and smart city evaluation.

Strategy, not technology, drives digital transformation (KANE et al., 2015). Our framework addresses strategy, design, implementation, evaluation, and use of smart cities initiatives. It is used to characterize how to envision a smart city and to design and assess smart transformation strategy. This research presents a smart city integrated approach, which comprises a platform to support and monitor the building of a smart city. The methodology is consisting of three phases: strategic vision, action plan, and management strategy. The paper 
presents an interesting framework for smart city evaluation. This evaluation framework is based on a list of meaningful KPIs that helps a city assess its smart transformation. It is a continual process of improvement that scrutinizes the city's positioning in terms of its competitiveness, ICT capabilities and the quality of its smart services.

The paper is structured as follows: the next section explores related works, followed by a section describing the smart city methodological framework, followed by conclusion and suggestions for future research.

\section{RELATED WORKS}

\subsection{Digital Strategy}

A digital strategy is required for a successful city's transformation into a smart city. What makes digital transformation different for cities compared to organizations? There may be a difference between the two transformations, but there is certainly something in common between them. There have been relevant works related to the digital transformation of organizations that can help in cities' digital transformation.

Successful digital transformation is based on a common set of elements (Eder, 2017). Each is a lever you can use to initiate and drive digital transformation in your organizations. Leaders diagnose the potential value of existing corporate assets and build a transformative vision for the future. Then, invest in skills and initiatives to make the vision a reality. Fundamental to the transformation is effective communication, evaluation, and governance to ensure that your firm is moving in the right direction. These common elements are summarized in this work in the following three steps: strategic vision, action plan, and management strategy.

There are differences between digitalization and digitization (Gobble, 2018). In short, digitization is the conversion of atoms to bits (replacing paper with electronic files). Digitalization is the transformation of all those bits into value. Digitization may deliver some savings, most commonly through efficiency gains and reduced error rates, but it doesn't change how the company does business-how it thinks about, creates, and delivers value. Digitalization is what cities need for transforming into smart cities. That kind of transformation doesn't happen by accident (Gobble, 2018). Digitalization is a journey, and a journey needs a map - in this case, a clear roadmap driven by a digital strategy. This roadmap is well expressed in the methodological framework presented in this work.

\subsection{Smart City Strategy}

Some researchers have developed frameworks and guides to cope with the challenge of digital transformation. Worldwide health organization has developed a National eHealth Strategy that helps to implement ICT in the health system to make it smarter (WHO and ITU, 2012). This strategy is based on the common elements of the digital transformation; however, several objections may be raised to it: it allows the use of ICT only in the health system and it does not offer a tool to facilitate the definition or evaluation of digital strategies. Creative cities such as Montreal rely on community-based and private sector initiatives, living labs, and social entrepreneurship. However, such cities lack the ability to steer and coordinate fragmented efforts (Ben Letaifa, 2015). Small and independent initiatives often fail to grow due to the lack of resources and formal leadership (Ben Letaifa, 2014).

London, Barcelona, Stockholm, and Amsterdam are four major European cities in the process of developing or implementing a smart city strategy (Angelidou, 2016). These smart initiatives are organized around different key themes: innovation, open data, leveraging research technology and creative talent, enabling smarter infrastructure development, and seeking to forge an open environment for collaboration among government, industry, academia, and citizens. Several works have studied frameworks that help organizations in thinking about digital strategy, or technologies that accelerate a given sector digital transformation (e.g. e-Health). However, there is a lack of research of operationalized concepts and models that guide organizations in thinking about strategy formation for driving competitive advantage in the digital age (Boström and Celik, 2019). This work is conceived to fill this gap by providing a methodological framework for defining and evaluating digital strategies for building smart cities. 


\subsection{Smart City Evaluation}

Transformation strategy should be revisited and evaluated on a regular basis and make sure that the action plan for implementing the strategy is on the right track. There are some city evaluation systems like DQSC-MM (Data Quality Driven Smart Cities Maturity Model) that focus on data quality for smart city evaluation (Korachi and Bounabat, 2018). Focusing on data in smart city assessment is very indeed important but not sufficient. A Real-Time Air Pollution Monitoring Systems has been implemented using Wireless Sensor Networks (Guanochanga et al., 2018). It is a very useful dashboard in case of air pollution but cities need an evaluation framework that takes into account all smart city dimensions. The most common smart city dimensions are smart economy, smart people, smart governance, smart mobility, smart environment, and smart living (Giffinger et al., 2007).

For an inclusive evaluation, smart cities can use real-time data. Smart city real-time data can be delivered on various platforms (Lange, 2018). How can cities take advantage of these indicators to monitor the progress of smart city initiatives? Real-time data can be used for smart cities ranking and benchmarking. They can be used by city dashboards to allow the city's users to get up-to-date information about a city and to help decision makers. A city dashboard consists of several modules, each of which contains a number of applications that display various data about the city (Mannaro et al., 2018). In this research, we have developed a smart city ranking system and a real-time dynamic dashboard that allows smart cities evaluation and monitoring.

\section{FRAMEWORK FOR DEFINING AND EVALUATING DIGITAL STRATEGIES FOR SMART CITY DEVELOPMENT}

In this section, we present a methodology for defining and evaluating digital strategies for building smart cities. This methodology allows establishing a digital strategy to effectively exploit the digital revolution for transforming the way people go about their everyday lives. The methodology consists of two frameworks. The first one is dedicated to defining the strategic plan for the city's smart transformation while the second is dedicated to assessing, ranking and benchmarking smart cities. The second one can evaluate transformation progress and identify the weaknesses and gaps in order to improve them in the next strategic planning.

\subsection{Smart City Strategy Framework}

The following figure (Fig.1) provides an overview of the phases and key components involved by the smart city strategy framework in the process of establishing a smart city strategic planning.

\begin{tabular}{|c|c|}
\hline $\begin{array}{c}\text { Strategic Vision } \\
\text { Definition }\end{array}$ & $\begin{array}{c}\text {-Stakeholders, Benchmarking, Trends, Goals, Changes, } \\
\text { Challenges, Weakness, Opportunities, Gaps and Resources }\end{array}$ \\
\hline Action Plan Elaboration & •Projects, Programs, and Activities \\
\hline $\begin{array}{c}\text { Management Strategy } \\
\text { Establishement }\end{array}$ & $\bullet \mathrm{KPls}$, Smart City Ranking, and Dashboard \\
\hline
\end{tabular}

Figure 1. Smart City Strategy Framework

\subsubsection{Strategic Vision Definition}

The first challenge of the smart transformation is to develop the strategic vision: determine why the city needs to be transformed into a smart city, what are changes and desired outcomes of this transformation, and what are resources required to perform the smart transformation. The following diagram (Figure 2) illustrates the strategic vision development process. 


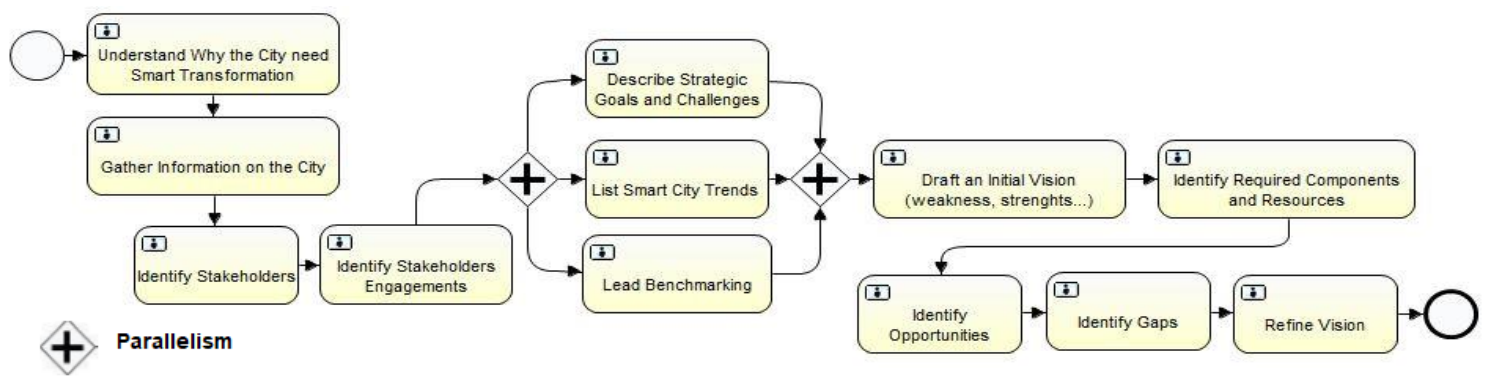

Figure 2. Strategic Vision Development Process

- Understand Why the City need Smart Transformation. Justify the contribution of ICTs in the city's transformation into a smart city and identify what are strategic objectives of the smart transformation.

- Gather Information on the City: Cities should study the existing system and the around environment to get a holistic view of the current state of the city and define the framework of the study and work.

- Identify Stakeholders and their Engagements. Successful stakeholder identification approaches initially require correct contextualization (Fritz et al., 2018). The stakeholders that are indirectly involved in the Smart City project are considered to be part of the operating environment (e.g., government agencies, local communities) and the broad environment (e.g., technological change, global political/legal forces) (Harrison and John, 1998).

- Describe Strategic Goals and Challenges. Describe in details smart city strategy goals and identify challenges that might face the smart transformation of the city. Example of challenges: cost, devices heterogeneity, diversity of technologies, interoperability, big data analysis, and information security.

- List Smart City Trends. learn from technologies and trends that have an impact on smart cities (Lea, 2017; Dodson, 2019): open data, e-participation, and smart technologies (e.g., internet of things, data analytics, cloud computing, artificial intelligence, city-wide digital platforms, greater real-time citizen interaction, linking autonomous vehicles with government sensors/networks, increased focus on human-centric technologies).

- Lead Benchmarking. Research into the experience of smart cities projects of other countries to learn from their successes and failures. Indeed, new smart cities are currently being developed such as (Pellicer et al., 2013; Anthopoulos, 2019): Songdo IBD in South Korea (Songdo.com, 2019), Meixi Lake in China (Madakam and Ramaswamy, 2016), Masdar city in Abu Dhabi (Alzaabi et al, 2018)(Masdar.ae, 2019), PlanIT Valley in Portugal, Skolkovo in Russia (Chudiniva and Afonina, 2018), Tampere (Business Tampere, 2019) and London (London City Hall, 2019).

- Draft an Initial Vision. The initial vision includes elements to focus on in building a successful smart transformation strategy. Steps to draft initial vision are: (1) determine city strengths and weaknesses, (2) identify the main components that will be introduced or strengthened through the transformation strategy (e.g., leadership, governance, investment, service, application, standard, interoperability, infrastructure, legislation, policy, compliance, workforce (WHO and ITU, 2012)), (3) define desired outcomes, changes, and impact of the smart transformation, (4) and identify required components for achieving desired goals and outcomes.

- Refine Vision. Identify opportunities and gaps, and refine the list of elements defined in the previous steps. To make a successful smart city, we need to be continually innovating and looking for opportunities.

\subsubsection{Action Plan Elaboration}

This section is intended to define the process for how a smart city action plan should be prepared to achieve the strategic vision. Strategic planning should be limited to the city as a whole, the businesses, and the important functions. A smart city action plan is a set of smart projects, programs, and activities.

A smart city action plan should determine success potentials. Determining success potentials is the main task of strategic planning (Grünig and Kühn, 2018). Strategic planning is not primarily concerned with optimizing success during the planning period itself. The focus is rather on determining the investments for maintaining existing success potentials and for building up new ones. Success potentials can be defined based on strategic vision elements (e.g. Do we have enough resources to implement the strategy?). The following diagram (Figure 3) presents the process to be followed to build an action plan for city transformation into a smart city. 


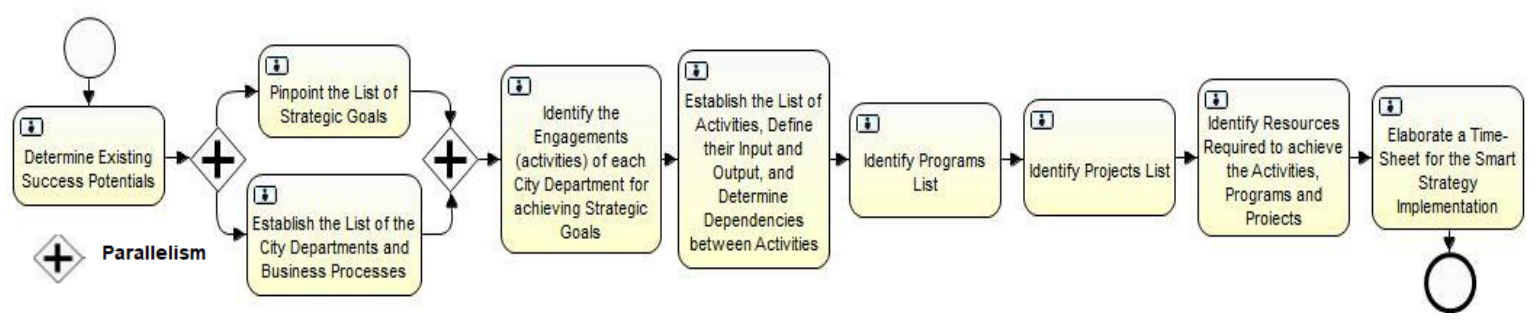

Figure 3. Action Plan Development Process

- Determine Existing Success Potentials. Existing success potentials should be defined in the strategy development phase whereas new success potentials are detected during strategy implementation.

- Pinpoint the List of Strategic Goals. This list is already defined in Phase1 (Strategic Vision Definition)

- Establish a List of City Departments and Business Processes. (e.g., Education and Environment).

- Identify the Engagements (activities) of each City Department for achieving Strategic Goals. Identify the expected engagements (activities) of each city business process in the achievement of strategic goals. Establish the List of Activities, Define their Input and Output, and Determine Dependencies between Activities. Dependencies between activities help to identify their logical sequence, expected duration, and it provides a basis for allocating management responsibility.

- Identify the Programs List. A program definition depends on the city and its context. A program can be a list of engagements per business processes or per strategic objectives.

- Identify the Projects List. A project is a set of programs. Based on the programs list identified in the step before, identify projects list and affect each program to the appropriate project.

- Establish the List of Resources Required to achieve the Activities, Programs, and Projects.

- Elaborate a Time-Sheet for the Smart Strategy Implementation. Elaborate a time sheet containing planning for projects, programs and activities (short-term, mid-term and long-term).

\subsubsection{Management Strategy Establishment}

The strategy should not be a two-step process, where one team creates a plan and another implements it, with little interaction between the two (Eder, 2017). A strategy is a continual process that needs management and monitoring. To monitor the smart transformation strategy, cities need a management strategy. This section is intended to define the process for how a smart city management strategy should be prepared.

Key Performance Indicators are useful tools for guiding urban development, by efficiently monitoring the sustainable evolution of cities. In this regard, an appropriate set of relevant indicators must be established and properly evaluated (Picioroaga et al., 2018). A management strategy should define a list of indicators that include the perspective of stakeholders and allow to monitor the action plan progress, assess smart strategy results, make appropriate decisions, and perform smart cities ranking and benchmarking.

Goal Question Metric (GQM) is a suitable approach to define relevant KPIs. It is a well-known paradigm proposed by Basili for defining the software measurements (Basili, 1993). The GQM approach identifies three steps. As suggested by its name, the GQM Approach provides a method for defining Goals, refining them into Questions and then defining the Metrics to collect data. This approach has been applied successfully in several contexts (Mannaro et al., 2018; Akbar et al., 2014; Basili et al., 2014; Behkamal et al., 2014; Southekal, 2017) and it will be successful also in the context of this work. GQM defines a top-down approach based on three levels: a conceptual level (Goal); an operational level (Question); and a quantitative level (Metric). This method will help to exploit KPIs for assessing strategic goals defined in the strategic vision. The following process (Fig.4) helps cities develop a management strategy.

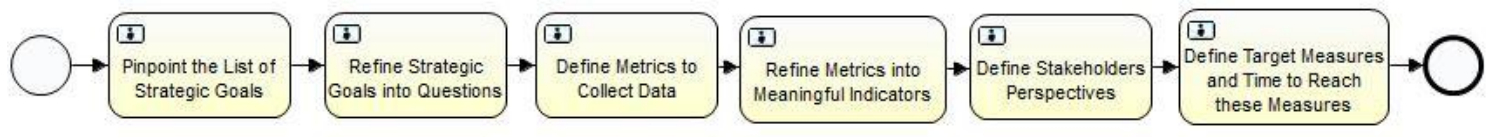

Figure 4. Management Strategy Development Process 


\subsection{Smart City Evaluation Framework}

Appropriate metrics are required in order to assess the contribution that ICTs are making toward smart development of cities. They are needed to measure progress, that is to establish the contribution that ICTs are making to overall social and economic progress as well as to environmental advancements (Lombardi, 2011). These metrics can be used also to help a city understanding exactly where it stands in relation to other cities so that it can establish a starting point in its transformation (Nabil, 2015). Cities need an evaluation framework allowing to exploit these metrics to monitor the contribution of smart initiatives and to perform benchmarking. The proposed smart city framework offers an evaluation system that allows for monitoring strategy progress, performing smart city benchmarking, and identifying the improvements points to deal with in the next strategic planning.

\subsubsection{Smart City Key Performance Indicators}

Key Performance Indicators allow the city to monitor the outcomes of long-term investments and evaluate their overall impact (Picioroaga et al., 2018). They allow smart cities benchmarking in order to learn from the experience of other smart cities.

In smart cities, the focus is not only on the ICT infrastructure but is mainly on the role of human capital, economy, education, social, and environment. This paper proposes a list of KPIs that enables a holistic smart city evaluation, it allows assessment based on smart city dimensions: smart economy, smart people, smart governance, smart mobility, smart environment, and smart living. Each of these dimensions provides a separate view of progress and when reported together provide a holistic view of a smart city (United Smart Cities, 2019). The KPIs list proposed in this work has been selected from the literature review (ITU-T FG-SSC, 2015b; Lombardi et al., 2012; United smart sustainable cities, 2019; Vogt et al., 2013; ITU-T FG-SSC, 2015c). Selection of this list of KPIs is performed based on the following characteristics: relevance, comprehensiveness, comparability, availability, independence, simplicity, and timeliness. AHP (Analytic Hierarchy Process (Teknomo, 2006)) Model is adopted in order to select the most relevant KPIs. The criteria tree model used in the selection procedure is presented in the diagram below (Figure 5):

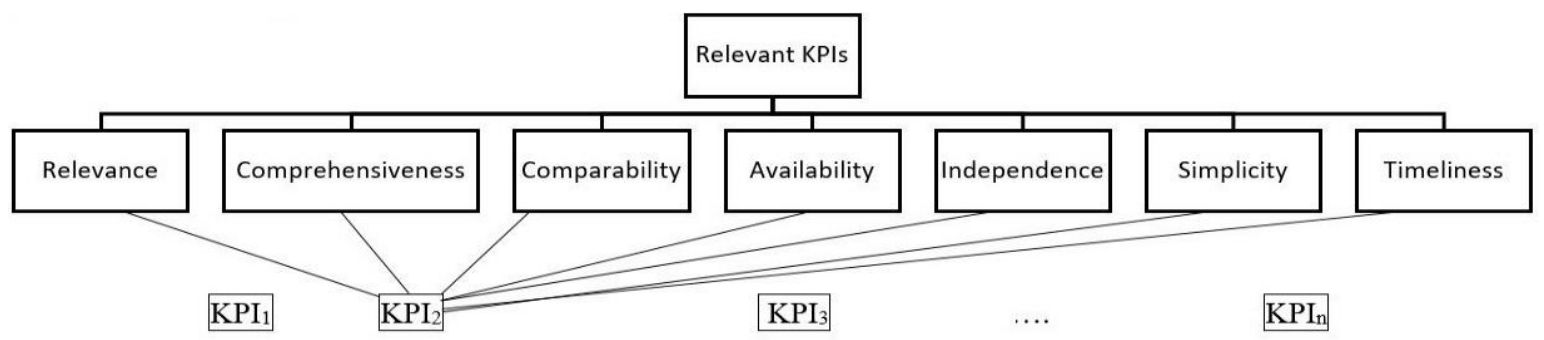

Figure 5. Relevant KPIs AHP Tree

Selected KPIs are presented in the following table (Tab.1) and they are classified according to smart city dimensions. The list cannot be regarded as final, it can be modified in line with policy and time changes and changes in availability, and/or cost-effectiveness of new measurement systems.

Table 1. Smart City KPIs

\begin{tabular}{ll}
\hline Dimension & \multicolumn{1}{c}{ Smart City Key Performances Indicators } \\
\hline Economy & $\begin{array}{l}\text { Network facilities: Household Internet Access; Fixed Broadband Subscriptions; Wireless Broadband } \\
\text { Subscriptions; Wireless Broadband Coverage; Availability of WIFI in Public Areas. }\end{array}$ \\
\cline { 2 - 2 } & $\begin{array}{l}\text { Information facilities: Percentage of enterprises providing network-based services (e-commerce, } \\
\text { e-learning, cloud computing); Proportion of business based on cloud computing; Proportion of business } \\
\text { based on GIS (Geographic Information System); Percentage of smart devices by person; Ratio of } \\
\text { children online protection; Level of cyber-security. }\end{array}$ \\
& $\begin{array}{l}\text { Water and Sanitation: Smart Water Meters; Water Supply ICT Monitoring; Drainage Water System } \\
\text { ICT Monitoring. }\end{array}$ \\
\cline { 2 - 2 } & $\begin{array}{l}\text { Electricity Supply: Smart Electricity Meters; Electricity Supply ICT Monitoring; Percentage of } \\
\text { renewable energy use; Electricity Saving; Electricity Production; Electricity Peak Response Capacity. }\end{array}$ \\
\hline
\end{tabular}


Innovation : Percentage of hackathons organized per year for the development of the city; Number of Small and Medium-Sized Enterprises; Number of new Enterprises per year; Statistics of entrepreneurs; R\&D (Research and Development) Expenditure; Patents; Ratio of knowledge-intensive enterprises; Revenue share of knowledge-intensive enterprise; SSC (Smart Sustainable City) new projects opportunities; Penetration of teleworking system; Improvement of traditional industry with ICT; Proportion of business based on Artificial Intelligence; Employment rate in knowledge-intensive sectors; Percentage of e-commerce transaction amount; Percentage of transaction by card Employment: Unemployment Rate; Youth Unemployment Rate; ICT Sector Employment

Living Convenience and comfort: Satisfaction with online commercial and financial services; Satisfaction with environmental safety; Convenience of government services; Convenience of smart traffic information administration and service; Satisfaction with quality of public transport; Satisfaction with crime prevention and security control; Satisfaction with countermeasures against disaster; Satisfaction with food drug safety monitoring; Convenience of urban medical care; Convenience for citizens to access education resource; Perception of proof against risk of poverty; Satisfaction with housing conditions

Security and safety: Accident prediction ratio; Penetration of ICT for disaster prevention; Publication rate of disaster alert; Penetration of city video surveillance; Natural Disaster Related Deaths; Disaster Related Economic Losses; Resilience Plans; Population Living in; Disaster Prone Areas; Emergency Service Response Time; Police Service; Fire Service; Violent Crime Rate; Local Food Production

Health care: Percentage of archiving electronic health records for residents; Usage rate of electronic medical records; Sharing rate of resource and information among hospitals; Coverage rate of household e-health services

Education and training: Effectiveness of hatching smart tech from knowledge centers (research centers, universities, etc.); Penetration of e-learning system; Percentage of courses downloadable from the internet

Mobility Dynamic Public Transport Information; Traffic Monitoring; Traffic Fatalities

Environment Air : Proportion of information published on environmental quality; Progress degree of ICT in the protection of city water resources; Effect of flood control monitoring by means of ICT measures; Proportion of water pollution control by means of ICT measures; Proportion of air pollution monitoring by means of ICT measures; Proportion of toxic substances monitoring by means of ICT measures; Proportion of noise monitoring by means of ICT measures

Water and Sanitation: Drinking Water Quality; Water Consumption; Freshwater Consumption; Wastewater Treatment; Solid Waste Treatment; Solid waste disposal management with ICT measures

Public Space and Nature: Green Areas; Green Area Accessibility; Protected Natural Areas; Recreational Facilities

Energy: Proposition of Electricity Consumption; Proposition of Residential Thermal Energy Consumption; Improvement of civilian electricity usage (per capita) with ICT measures; Improvement of industrial electricity usage with ICT measures; Improvement of civilian water usage (per capita) with ICT measures; Improvement of industrial water usage with ICT measures; Improvement of fossil fuel usage with ICT; Improvement of rare metal/noble metal usage with ICT measures

Governance Digital access to urban planning and budget document; Appliance of smart community services; Penetration rate of government online services; E-government usage by individuals; Percentage of government information open; Penetration of smart impediment removal (accessibility) system; No. of universities and research centers in the city; Proposition of open data

People Openness and public participation: Penetration of e-learning system; Improvement of turnout at city hearings by means of ICT; Online civic engagement; Feasibility of appealing online; Atmosphere of free online comment; Contribution in increasing consciousness of citizenship and social coherence

Education: Student ICT Access; School Enrollment; Higher Education Degrees; Adult Literacy

Health: Electronic Health Records; Life Expectancy; Maternal Mortality Rate; No. of Physicians per citizen; In-Patient Hospital Beds per citizen; Health Insurance / Public Health Coverage

Culture : Cultural Expenditure; Cultural Infrastructure

Housing: Informal Settlements

Social inclusion: Gender Income Equity; Rate of Poverty; Voter Participation; Child Care Availability

\subsubsection{Smart Cities Ranking}

To perform Smart Cities Benchmarking, we provide in this section a Smart Cities Ranking System. For calculating the rank (overall score) of a smart city the next steps have been followed: 


\section{1) Determine the Weights of Key Performance Indicators}

The AHP model helps us calculating KPIs weights using a scale from 1 to 9 (Teknomo, 2006), and using the criteria tree model illustrated in figure 5. KPIs weights should not be assigned by each city, they should be assigned by experts which allow the framework to be useful for benchmarking.

Constructing the judgment matrix. The importance of KPIs can be scaled, using numeric values from 1 to 9.1 is associated with equally important KPIs, 3 is accorded when KPI $i$ is slightly more important than j, 5 when $i$ is more important than $j, 7$ when $i$ is strongly more important than $j$, and 9 when $i$ is absolutely more important than $\mathrm{j}$, while 2, 4, 6 and 8 are associated with intermediate situations (Teknomo, 2006). The pairwise comparison matrix, $\mathrm{A}=($ aij)nxn, is structured as follows (Teknomo, 2006):

$$
A=\left(\begin{array}{cccc}
a_{11} & a_{12} & \cdots & a_{1 n} \\
a_{21} & a_{22} & \cdots & a_{2 n} \\
\vdots & \vdots & \ddots & \vdots \\
a_{n 1} & a_{n 2} & \cdots & a_{n n}
\end{array}\right)
$$

$n$ : the number of KPIs to be evaluated; aij: the importance of the KPI I according to KPI $j$.

Estimating the relative weights. Once the judgment matrix is constructed, the relative weights (priorities) of KPIs are estimated, computing the normalized Eigen Vector (W) of the matrix (Teknomo, 2006).

2) City Rank

City rank is the scalar product of the weight vector and the vector of values obtained by the city for each KPI.

$$
\mathrm{R}=\sum_{\mathrm{j}=1}^{\mathrm{n}}(\mathrm{Vj} * \mathrm{Wj})
$$

$\boldsymbol{R}$ : the rank of the city; $\mathrm{Vj}$ : the value obtained by the city for KPI $j ; \mathrm{Wj}$ : the associated weight for KPI $j$; $\boldsymbol{n}$ : the number of evaluated KPIs.

\subsubsection{Smart Cities Evaluation}

To evaluate the progress of smart city projects and control the achievement of strategic goals, we should collect strategic goals identified in the previous steps (strategic vision) and adopt the GQM method to define a set of KPIs for each strategic goal. These KPIs will allow assessing and monitoring the achievement of the associated strategic goal using Control Theory in order to control the variation and development of KPIs measurements at any moment of time. The control theory studies the possibility of acting on a dynamical system dependent on the temporal variable in order to lead the state of this system to a given state at a given instant. The dynamical system in this work is $\mathrm{R}_{\mathrm{SgObj}}$ vector, it is the ranking vector of KPIs, it provides a clear idea of the reality of achievement of the strategic goals at a specific moment in time.

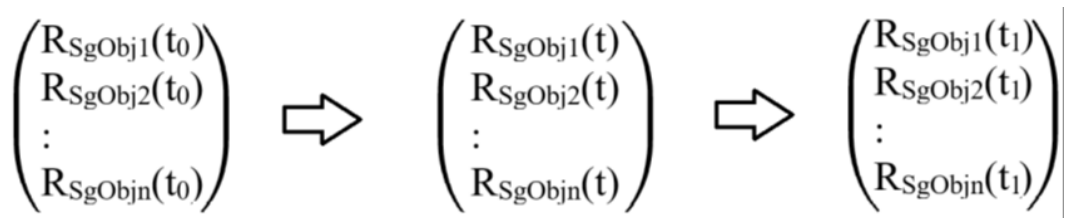

\section{As Is}

\section{To Be}

$\boldsymbol{R}_{S g O b j i}=\sum_{j=1}^{m_{j}}(\boldsymbol{V j} * \boldsymbol{W j}):$ Rank of KPIs associated to the strategic goal $i ; \boldsymbol{n}:$ Number of strategic goals; $\boldsymbol{m}:$ Number of KPIs associated to the strategic goal $i$; $t_{0}$ : The initial moment; $t_{1}$ : Moment of reaching objective values of KPIs

\subsubsection{Smart City Dashboard}

A city dashboard is a big data platform designed, on the one hand, to allow city's users to get up-to-date information about a city and, on the other hand, to give access to a wide range of datasets about the city to help decision makers (Mannaro et al., 2018). The design of a city dashboard needs a clear vision of the direction that public administrations intend to undertake, alongside an ability to build scenarios and analyze the results of experiments in the context of the changing urban variables.

We may differentiate between ways of displaying information on dashboards, via charts and graphs, diagrams or maps (Kitchin at al., 2015). Distinctions can further be made between indexical interfaces, with a 
direct reference to the measured object (e.g. an electricity meter), and symbolic interfaces that involve a further translation (e.g. an alarm light indicating an empty tank) (Mattern, 2015), between fixed and interactive visualizations (Kitchin at al., 2015), and between dynamically refreshing or cumulative ones. The evaluation framework proposed in this work offers a real-time dynamic smart city dashboard. It illustrates smart KPIs in the form of a smart city performance map. Each KPI is presented in the appropriate form depending on its signification (line chart, bar chart ...). The platform will use network sensors to capture city KPIs measurement. Sensors are placed at the appropriate places in the city to capture real-time data. The architecture of the dashboard system includes network sensors, servers, internet and Remote Terminal Unit (Suakanto et al., 2013). RTUs are used to send data captured by sensors to servers via the internet.

\section{CONCLUSION}

Digital transformation is not about a digital department and a mobile strategist won't save your organization. It's a philosophy that all must adopt (Eder, 2017). Smart city strategy is needed to achieve the smart city strategic goals and advance the city's strategic vision.

This paper presents a smart city integrated approach, which comprises a platform and dashboard to support and monitor the building of a smart city. A list of KPIs is provided to help a city assess its transformation and perform benchmarking via calculating smart city ranking. These KPIs will be used in our next research to create customized maturity models for evaluating the maturity level of smart cities. To facilitate the use of the proposed smart city methodological approach, we started the development of a software framework supporting this methodology. This framework provides stakeholders the ability to establish a strategy for city transformation into a smart city. It helps to mind mapping, boost productivity, creativity, and memory to develop a digital strategy for building a smart city. The development of the framework is in progress and it will be used by Smart Agdal Region when it is completed.

Here we list several promising future research directions:

- Use the provided list of KPIs to create maturity models for smart city assessment.

- Use artificial intelligence to transform the smart city framework into a knowledge-based system.

\section{REFERENCES}

Akbar, M., Sukmana, H. T., \& Khairani, D. (2014). Models and software measurement using Goal/Question/Metric method and CMS Matrix parameter (Case study discussion forum). In 2014 International Conference on Cyber and IT Service Management (CITSM)(pp. 34-38). South Tangerang.

Alzaabi, M., Rizk, Z. and Mezher, T. (2018). Linking Smart Cities Concept to Energy-Water-Food Nexus: The Case of Masdar City in Abu Dhabi, UAE. Smart Cities in the Gulf, pp.85-106.; https://doi.org/10.1007/978-981-13-2011-8_6.

Angelidou, M. (2016). Four European Smart City Strategies. International Journal of Social Science Studies, 4(4); ISSN 2324-8033E-ISSN 2324-8041; doi:10.11114/ijsss.v4i4.1364.

Anthopoulos, L. (2019). Smart utopia VS smart reality: Learning by experience from 10 smart city cases. Business School, TEI of Thessaly, Greece, Larissa, ring road, GR41110 Larissa, Greece, http://dx.doi.org/10.1016/j.cities.2016.10.005.

Basili, V. R. (1993). Applying the Goal/Question/Metric paradigm in the experience factory (pp. 21-44). Software Quality Assurance and Measurement: A Worldwide Perspective.

Basili, V., Heidrich, J., Lindvall, M., Münch, J., Regardie, M., Rombach, D., \& Trendowicz, A. (2014). GQM + Strategies: A comprehensive methodology for aligning business strategies with software measurement. Proceedings of the DASMA Software Metric Congress (MetriKon 2007): Magdeburger Schriften zum Empirischen Software Engineering, pages 253-266, Kaiserslautern, Germany, November 15-16 2007.

Behkamal, B., Kahani, M., Bagheri, E., \& Jeremic, Z. (2014). A metrics-driven approach for quality assessment of linked open data. Journal of Theoretical and Applied Electronic Commerce Research, 9(2), 64-79.

Ben Letaifa, S. (2014). The uneasy transition from supply chains to ecosystems. Management Decision, 52(2), pp.278-295.

Ben Letaifa, S. (2015). How to strategize smart cities: Revealing the SMART model. Journal of Business Research, 68(7), pp.1414-1419.

Boström, E. and Celik, O., C. (2017). Towards a Maturity Model for Digital Strategizing A qualitative study of how an organization can analyze and assess their digital business strategy. Department of informatics IT Management Master thesis 2-year level, 30 credits SPM 2017.09. 
Brunelli, M. (2015). Introduction to the Analytic Hierarchy Process. SpringerBriefs in Operations Research. P. 83. 978-3-319-12502-2. 10.1007/978-3-319-12502-2. Available at: https://core.ac.uk/download/pdf/80714029.pdf [Accessed 17 Jun. 2019].

Budde, P. (2019). 2015 Australia - E-Health, E-Education, E-Government. [online] Budde.com.au. Available at: https://www.budde.com.au/Research/2015-Australia-E-Health-E-Education-E-Government [Accessed 1 Apr. 2019].

Business Tampere. (2016). Tampere, Finland, is investing 6-10 Billion Euro in development of smarter city by 2030 - Smart Tampere possibilities on display at the Smart City Expo World Congress in Barcelona - Business Tampere Magazine. [online] Available at: https://businesstampere.com/tampere-finland-is-investing-6-10-billioneuro-in-development-of-smarter-city-by-2030-smart-tampere-possibilities-on-display-at-the-smart-city-expo-worldcongress-in-barcelona/ [Accessed 17 Jun. 2019].

Chourabi, H., Nam, T., Walker, S., Gil-Garcia, J., Mellouli, S., Nahon, K., Pardo, T. and Scholl, H. (2012). Understanding Smart Cities: An Integrative Framework. 2012 45th Hawaii International Conference on System Sciences. doi:10.1109/hicss.2012.615.

Chudiniva, O. and Afonina, M. (2018). Formation of "Urban planning" indicators for "Smart City" concept (on the example of SKOLKOVO, Moscow). MATEC Web of Conferences, 170, p.02021.; https://doi.org/10.1051/matecconf/201817002021.

Dodson, K. (2019). Top 10 Smart City Trends for 2018. [online] blogs@Cisco - Cisco Blogs. Available at: https://blogs.cisco.com/government/top-10-smart-city-trends-for-2018 [Accessed 17 Jun. 2019].

Eder, M. (2017). Common elements of a successful digital strategy. Available at https://www.researchgate.net/publication/322078143_COMMON_ELEMENTS_OF_A_SUCCESSFUL_DIGITAL_ STRATEGY.

Fritz, M., Rauter, R., Baumgartner, R. and Dentchev, N. (2018). A supply chain perspective of stakeholder identification as a tool for responsible policy and decision-making. Environmental Science \& Policy, 81, pp.63-76. doi:10.1016/j.envsci.2017.12.011.

Giffinger, R.,Fertner, C.,Kramar, H., Kalasek, R., Pichler-Milanović, N., Meijers, E. (2007). Smart cities - Ranking of European medium-sized cities. [online] Centre of Regional Science (SRF), Vienna University of Technology in October 2007. Available at: http://www.smart-cities.eu/download/smart_cities_final_report.pdf [Accessed 17 Jun. 2019].

Gobble, M. (2018). Digital Strategy and Digital Transformation. Research-Technology Management, 61(5), pp.66-71.

Grünig, R. and Kühn, R. (2018). Strategic Planning. The International Encyclopedia of Strategic Communication, pp.1-11. Robert L. Heath and Winni Johansen (Editors-in-Chief), Jesper Falkheimer, Kirk Hallahan, Juliana J. C. Raupp, and Benita Steyn (Associate Editors). (C) 2018 John Wiley \& Sons, Inc. Published 2018 by John Wiley \& Sons, Inc. DOI: 10.1002/9781119010722.iesc0177.

Guanochanga, B., Cachipuendo, R., Fuertes, W., Benitez, D. S., Toulkeridis, T., Torres, J., ... Meneses, F. (2018). "Towards a RealTime Air Pollution Monitoring Systems Implemented using Wireless Sensor Networks: Preliminary Results". 2018 IEEE Colombian Conference on Communications and Computing (COLCOM). doi:10.1109/colcomcon.2018.8466721.

Harrison, J.S., John St, C.H., (1998). Strategic Management of Organizations and Stakeholders: Concepts and Cases, 2nd ed. Southwestern College Publishing, Cincinnati, OH.

ITU-T FG-SSC (2015a). Master plan for smart sustainable cities. [online] Focus Group Technical Report. Available at: https://www.itu.int/en/ITU-T/focusgroups/ssc/Documents/website/web-fg-ssc-0314-r5-ssc_framework.docx [Accessed 17 Jun. 2019].

ITU-T FG-SSC (2015b). Key performance indicators definitions for smart sustainable cities. [online] Focus Group Technical Report. Available at: https://www.itu.int/en/ITU-T/focusgroups/ssc/Documents/website/web-fg-ssc-0100r9-definitions_technical_report.docx [Accessed 17 Jun. 2019]. (ITU-T Focus Group on Smart Sustainable Cities, 2015).

ITU-T FG-SSC (2015c). Key performance indicators related to the use of information and communication technology in smart sustainable cities. [online] Focus Group Technical Report. Available at: https://www.itu.int/en/ITUT/focusgroups/ssc/Documents/website/web-fg-ssc-0268-r5-KPIs_ICT.docx [Accessed 17 Jun. 2019].

Kane, G., Palmer, D., Phillips, A., Kiron, D. and Buckley, N. (2015). Strategy, not Technology, Drives Digital Transformation. [online] MIT Sloan Management Review. Available at: https://sloanreview.mit.edu/projects/strategy-drives-digital-transformation/ [Accessed 17 Jun. 2019].

Kanter, R. and Litow, S. (2009). Informed and Interconnected: A Manifesto for Smarter Cities. In: Harvard University Advanced Leadership Initiative Think Tank on Poverty, Justice, and Jobs. [online] USA, p.https://hbswk.hbs.edu/item/informed-and-interconnected-a-manifesto-for-smarter-cities. Available at: https://www.hbs.edu/faculty/Publication\%20Files/09-141.pdf [Accessed 17 Jun. 2019].

Kitchin, R., Lauriault, T. and McArdle, G. (2015). Knowing and governing cities through urban indicators, city benchmarking and real-time dashboards. Regional Studies, Regional Science, 2(1), pp.6-28. 
Korachi, Z. and Bounabat, B. (2018). Data Driven Maturity Model for Assessing Smart Cities. ICSDE'18, October 18-20, 2018, Rabat, Morocco; (C) 2018 Association for Computing Machinery; ACM ISBN 978-1-4503-6507-9/18/10; ENSIAS Rabat; Morocco.

Lange, M. (2018). From real-time city to asynchronicity. Time for mapping. https://doi.org/10.7765/9781526122520.00021.

Lea, R. (2017). Smart Cities: An Overview of the Technology Trends Driving Smart Cities. IEEE, licensed under a Creative Commons Attribution-Non-Commercial 3.0 United States License.

Lombardi P. (2011). New challenges in the evaluation of Smart Cities. In: NETWORK INDUSTRIES QUARTERLY, vol. 13 n. 3, pp. 8-10. - ISSN 1662-6176.

Lombardi, P., Giordano, S., Farouh, H. and Yousef, W. (2012). Modelling the smart city performance. http://dx.doi.org/10.1080/13511610.2012.660325; Innovation - The European Journal of Social Science Research Vol. 25, No. 2, June 2012, 137-149.

London City Hall. (2019). Smarter London Together. [online] Available at: https://www.london.gov.uk/what-wedo/business-and-economy/supporting-londons-sectors/smart-london/smarter-london-together [Accessed $17 \quad$ Jun. 2019].

Madakam, S. and Ramaswamy, R. (2016). Smart Cities [Meixi (China) $\times$ Kochi (India)] Notions (Sustainable Management Action Resource Tools for Cities). Advanced Computing and Communication Technologies, pp.269-277. DOI 10.1007/978-981-10-1023-1_27.

Mannaro, K., Baralla, G. and Garau, C. (2018). A Goal-Oriented Framework for Analyzing and Modeling City Dashboards in Smart Cities. Smart and Sustainable Planning for Cities and Regions, pp.179-195. doi:10.1007/978-3-319-75774-2_13.

Masdar.ae. (2019). Home. [online] Available at: https://masdar.ae/en [Accessed 17 Jun. 2019]. MASDAR CITY in Abu Dhabi.

Mattern, S. (2015). Mission control: A history of the urban dashboard.Places Journal, March. [Online] Available at: https://placesjournal.org/article/mission-control-a-history-of-the-urban-dashboard/ [Accessed 01 Jun. 2019].

Nabil, A. (2015). Action plan for a smart city. [online] Fr.slideshare.net. Available at: https://fr.slideshare.net/AhmedMohamedNabil/action-plan-for-a-smart-city-45796767 [Accessed 17 Jun. 2019].

Pellicer, S., Santa, G., Bleda, A., Maestre, R., Jara, A. and Skarmeta, A. (2013). A Global Perspective of Smart Cities: A Survey. 2013 Seventh International Conference on Innovative Mobile and Internet Services in Ubiquitous Computing.

Picioroaga, I., Eremia, M. and Sanduleac, M. (2018). SMART CITY: Definition and Evaluation of Key Performance Indicators. 2018 International Conference and Exposition on Electrical And Power Engineering (EPE).doi:10.1109/icepe.2018.8559763.

Songdo.com. (2019). [online] Available at: http://songdo.com/ [Accessed 17 Jun. 2019]. (Songdo.com, 2019)

Southekal, P. (2017). Data for business performance: The goal-question-metric (GQM) model to transform business data into an enterprise asset. Published February 15th 2017 by Technics Publications, LLC. ISBN 1634621840 (ISBN13: 9781634621847).

Suakanto, S., Supangkat, S., Suhardi and Saragih, R. (2013). Smart city dashboard for integrating various data of sensor networks. International Conference on ICT for Smart Society. doi:10.1109/ictss.2013.6588063.

Teknomo, K. (2006). Analytic hierarchy process (AHP) tutorial. Revoledu. com. Available at: https://www.researchgate.net/profile/Rafik_Karaman/post/there_is_any_details_about_AHP_method/attachment/59d 63b9179197b80779989cd/AS:411365203300368@1475088515401/download/AHP_Tutorial.pdf [Accessed 17 Jun. 2019].

UN DESA. (2018). 2018 Revision of World Urbanization Prospects $\mid$ Multimedia Library - United Nations Department of Economic and Social Affairs. [online] Available at: https://www.un.org/development/desa/publications/2018revision-of-world-urbanization-prospects.html [Accessed 5 Jun. 2019].

United Smart Cities, (2019). The way to become a Smart Sustainable City - News - United Smart Cities. [online] United Smart Cities. Available at: http://www.unitedsmartcities.org/news/the-way-to-become-a-smart-sustainable-city-34/ [Accessed 17 Jun. 2019].

United smart sustainable cities (2017). Collection Methodology for Key Performance Indicators for Smart Sustainable Cities. [online] Available at: https://www.itu.int/dms_pub/itu-t/opb/tut/T-TUT-SMARTCITY-2017-9-PDF-E.pdf [Accessed 17 Jun. 2019]. ISBN 978-92-61-25221-2 (Paper version); 978-92-61-25231-1 (Electronic version). Published in Switzerland Geneva, 2017.

Vogt, G., Dashja, E., Robinson, S. (2013). KPIs for S.M.A.R.T. Cities, DOI: 10.2759/42792, Proceedings of the 1st Workshop organised by the EEB Data Models Community ICT for Sustainable Places. Nice, France, 9 th -11 th September, 2013.

WHO (World Health Organization) and ITU (International Telecommunication Union), (2012). National eHealth Strategy Toolkit. 